\title{
Balancing Thermal and Electrical Packaging Requirements for GaN Microwave and Millimeter-Wave High Power Amplifier Modules
}

\author{
Rick Sturdivant1, Astacian Bogdon'1, Edwin K. P. Chong² \\ ${ }^{1} \mathrm{MPT}$, Inc., Fullerton, CA, USA \\ ${ }^{2}$ Department of Electrical and Computer Engineering, Colorado State University, Fort Collins, CO, USA \\ Email: ricksturdivant@gmail.com
}

How to cite this paper: Sturdivant, R., Bogdon, A. and Chong, E.K.P. (2017) Balancing Thermal and Electrical Packaging Requirements for GaN Microwave and Millimeter-Wave High Power Amplifier Modules. Journal of Electronics Cooling and Thermal Control, 7, 1-7.

https://doi.org/10.4236/jectc.2017.71001

Received: November 17, 2016

Accepted: January 15, 2017

Published: January 18, 2017

Copyright $\odot 2017$ by authors and Scientific Research Publishing Inc. This work is licensed under the Creative Commons Attribution International License (CC BY 4.0).

http://creativecommons.org/licenses/by/4.0/

(c) $\underset{\mathrm{EY}}{(i)}$ Open Access

\begin{abstract}
A method for balancing thermal and electrical packaging requirements for gallium nitride $(\mathrm{GaN})$ high power amplifier (HPA) modules is presented. The goal is to find a design approach that minimizes the junction temperature of the $\mathrm{GaN}$ so that it is reliable and has interconnects that meet electrical performance requirements. One benefit of $\mathrm{GaN}$ is that it can simultaneously achieve high power density and operate at microwave and millimeter-wave frequencies. However, the power density can be so high that the necessary thermal solutions can have negative impact on electrical performance. This is especially a concern for the electrical interconnects required for the input/ output ports on high power amplifier devices. This is because the signal interconnects must operate at $\mathrm{GHz}$ frequencies, which means that special care must be taken to avoid problems such as undesired signal coupling and ground path inductance. Therefore, this work focuses on GaN packaging and its integration into a module. The results show that an optimum thickness for the GaN heat spreader exits for thermal performance but the electrical design is impacted negatively if the optimum thermal design is chosen. Therefore, a balanced design is chosen which meets overall system level requirements.
\end{abstract}

\section{Keywords}

Thermal Design, GaN Amplifier, Balanced Design, Electric Interconnects

\section{Introduction}

High power amplifiers (HPAs) are an important part of systems and are widely used. For instance, they are used in weather satellites, radar systems for air traffic 
control, satellite television broadcasts, satellite radio, military radar, wireless backhaul for internet traffic, mobile phones, mobile phone cell towers, and many more. In addition, the amplifiers must remain reliable for many years (decades, in fact). One of the most important determining factors for reliability is the operating temperature of the devices. To remain reliable, HPAs must be designed so that their operating temperatures (device junction temperature) remain below the required level for reliable operation. This is achieved, in part, by proper heat spreader implementation.

The heat spreader is physically connected to the heat generating devices in the HPAs so they can spread the heat generated in device junctions. The heat density generated in the FET junctions of gallium nitride $(\mathrm{GaN})$ amplifiers can be as high as $3200 \mathrm{~W} / \mathrm{cm}^{2}$, which more than two orders of magnitude higher heat density than the average clothing iron turned to its highest temperature. Managing this thermal load requires heat spreaders that are often large compared to the wavelength of operation. As a result, proper heat spreader design is critical to achieve reliable operation.

Prior work has shown electrical packaging can often dictate the performance of a product operating at microwave and millimeter-wave frequencies. For instance, in [1] it was shown that interconnects between the active devices must be optimized which often means that the connections must be short and small relative to the wavelength of operation. Prior work has also shown the benefits of $\mathrm{GaN}$ amplifiers to achieve high RF output power and some thermal management methods. In [2] it was shown that output power from GaN hybrid amplifiers can be many times higher than competing semiconductor technology such as gallium arsenide (GaAs). In [3] it was shown that $15 \mathrm{~W}$ of output power is possible with GaN even at Ka band. An example of microfluidic cooling methods for GaN was investigated in [4] which showed that optimum flow rates can significantly improve GaN output power. A more conventional approach to thermal management was taken in [5] which mounted the GaN amplifiers on copper tungsten $(\mathrm{CuW})$ heat spreaders in a hybrid module for satellite communication systems. This prior work demonstrates the importance of the electrical packaging and thermal design of GaN amplifiers.

However, prior work does not address the challenges of simultaneous thermal design and electrical design of GaN packaging. Thermal and electrical requirements for HPA packaging and modules must be balanced to meet overall system performance goals. This work investigates this balance for a particular HPA package type. Section 2 describes package type being considered in this analysis and the GaN device being used. Section 3 shows that an optimum thickness of the heat spreader exists for some modules, which achieves the minimum device junction temperature. Section 4 describes the electrical interconnect performance as a function of heat spreader thickness and illustrates that the ground inductance increases as the heat spreader thickness increases. Section 5 describes the balanced design solution. Section 6 shows the conclusions of this investigation. 


\section{GaN Device and Package Type Chosen for Analysis}

GaN field effect transistor (FET) devices and monolithic microwave integrated circuits (MMICs) are packaged using a wide variety of materials and physical configurations. For instance, a plastic package was used for a $100 \mathrm{~W}$ GaN power amplifier [6] as a method to achieve low cost. Liquid crystal polymer (LCP) packaging was used in [7] along with stud bumped GaN devices. The approaches result in acceptable junction temperatures for reliable operation for applications that function at low duty cycle or low RF output power levels.

Another approach to the packaging of GaN devices uses a high thermal conductivity metal base and direct die attach to it. This type of package is described in [8] [9] and is illustrated in Figure 1.

GaN devices can be individual FET devices or they can be MMICs. The benefit of the MMIC is that it has all, or most, of the required matching and bias circuitry integrated into it. It also can have multiple stages of amplifiers to increase its signal gain. This means that it can generate high output power when driven by lower signal power levels. However, MMICs require more semiconductor area to fit all the required functions. Since semiconductor cost is roughly proportional to its area, MMICs tend to be higher cost than FET devices. Our analysis will focus on using a FET device with the following parameters.

- $\mathrm{FET}_{\mathrm{X}}=$ dimension of the GaN FET devices in the $\mathrm{x}$-direction $=0.8 \mathrm{~mm}$.

- $\mathrm{FET}_{\mathrm{Y}}=$ dimension of the GaN FET devices in the $\mathrm{x}$-direction $=1.5 \mathrm{~mm}$.

- Max Output Power $=25 \mathrm{~W}$.

- Material $=\mathrm{GaN}$ on $\mathrm{SiC}$ base.

- $\theta_{j c}=$ junction to case (junction to bottom of die) thermal resistance $\left({ }^{\circ} \mathrm{C} / \mathrm{W}\right)=$ 4.7 to 12.2 .

Note that the thermal resistance, $\theta_{j c}$, is provided by the fabricator of the GaN FET device.

\section{Heat Spreader}

A heat transfer analysis study was conducted to determine the optimum heat

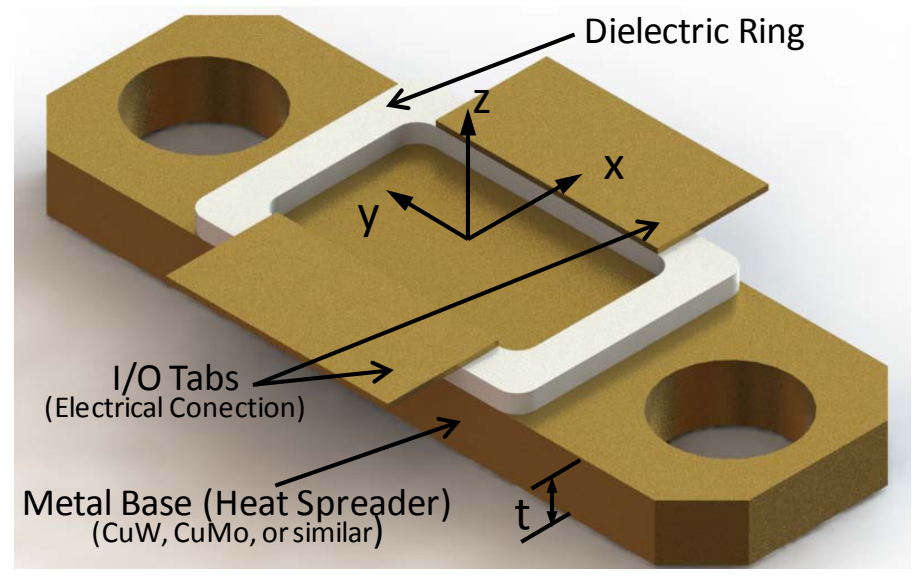

Figure 1. Module HPA package used for thermal analysis and electromagnetic simulations. 
spreader dimensions. For the purposes of the study, only conduction was considered as the heat transfer mechanism. Radiation and convection were ignored. The choice of dimensions immediately presents the designer who is seeking a balanced designed with several choices.

1) The $x$-axis dimension of the heat spreader must be chosen to optimize the length of the wire bond interconnect from the device to the package. The optimized size is normally the minimum that can be achieved for GaN FET die fit and die attach so that the wire bonds are as short as possible. Short wire bonds have less inductance than longer ones and they minimize the radiation which causes undesired stray coupling in the package. For optimum heat transfer, the $\mathrm{x}$-dimension may need to be larger than can be accommodated by the wire bond requirement.

2) The y-axis dimension of the heat spreader is also chosen primarily for fit and assembly reasons. That said, a package that is too small in the y-direction can also have non-optimum heat transfer characteristics.

3) The z-axis dimension (thickness) of the package will be considered in detail in the next section. The goal is to determine the optimum thickness, $t$, of the heat spreader that will provide the lowest thermal resistance.

In practice, the $\mathrm{x}$ and $\mathrm{y}$ dimensions of the heat spreader are often set by standard package sizes from suppliers. This is especially true if a pre-packaged amplifier (from the manufacturer) is chosen.

\section{Optimum Heat Spreader Thickness for Thermal Performance}

The optimum heat spreader thickness was investigated using 3D finite element method (FEM) simulations. The cross section of the structure that was analyzed is illustrated in Figure 2. This configuration is important since most high power amplifier packages are mounted into a housing or onto a pallet. The optimum thickness of the heat spreader depends upon the material properties (and physical dimensions) of housing. The heat source is the FET devices with dimensions $\mathrm{FET}_{\mathrm{X}}=0.8 \mathrm{~mm}$ and $\mathrm{FET}_{\mathrm{Y}}=1.5 \mathrm{~mm}$. These dimensions correspond to the size of the GaN die shown in Figure 2.

The FEM simulation assumed a thickness for the housing base of $2.5 \mathrm{~mm}$ since this is in the range of typical values. Three housing materials were considered: 6061 aluminum $(k=170 \mathrm{~W} / \mathrm{mK})$, cold rolled steel (CRS) $(k=51.9$ $\mathrm{W} / \mathrm{mK})$, and Kovar $(k=17.3 \mathrm{~W} / \mathrm{mK})$. Where $k$ is the thermal conductivity of the material. The thickness of the heat spreader was varied from $0.1 \mathrm{~mm}$ to $10 \mathrm{~mm}$

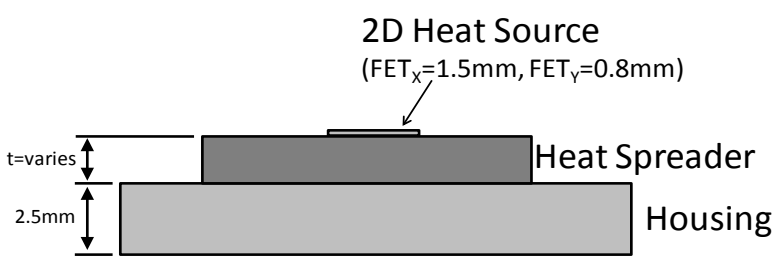

Figure 2. Simplified cross section of the material stack up used in the 3D finite element method (FEM) heat transfer analysis. 
and the heat spreader material was taken to be $\mathrm{CuW}(80 \% \mathrm{~W}, 20 \% \mathrm{Cu}, k=206$ $\mathrm{W} / \mathrm{mK}$ ). For the FEM simulations, the mesh control on the heat source was set to $0.01 \mathrm{~mm}$. For the rest of the model, the mesh min element size of set to 0.01 $\mathrm{mm}$ and mesh max element size was set to $0.5 \mathrm{~mm}$.

The temperature profiles from FEM simulations are shown in Figure 3. The figure is for the case of an aluminum 6061 base with a $1 \mathrm{~mm} \mathrm{CuW} \mathrm{(20/80)} \mathrm{heat}$ spreader. Note that the temperature gradient illustrates a max temperature of $2.36^{\circ} \mathrm{C}$.

The results of the heat transfer analysis are shown in Figure 4. Note from the

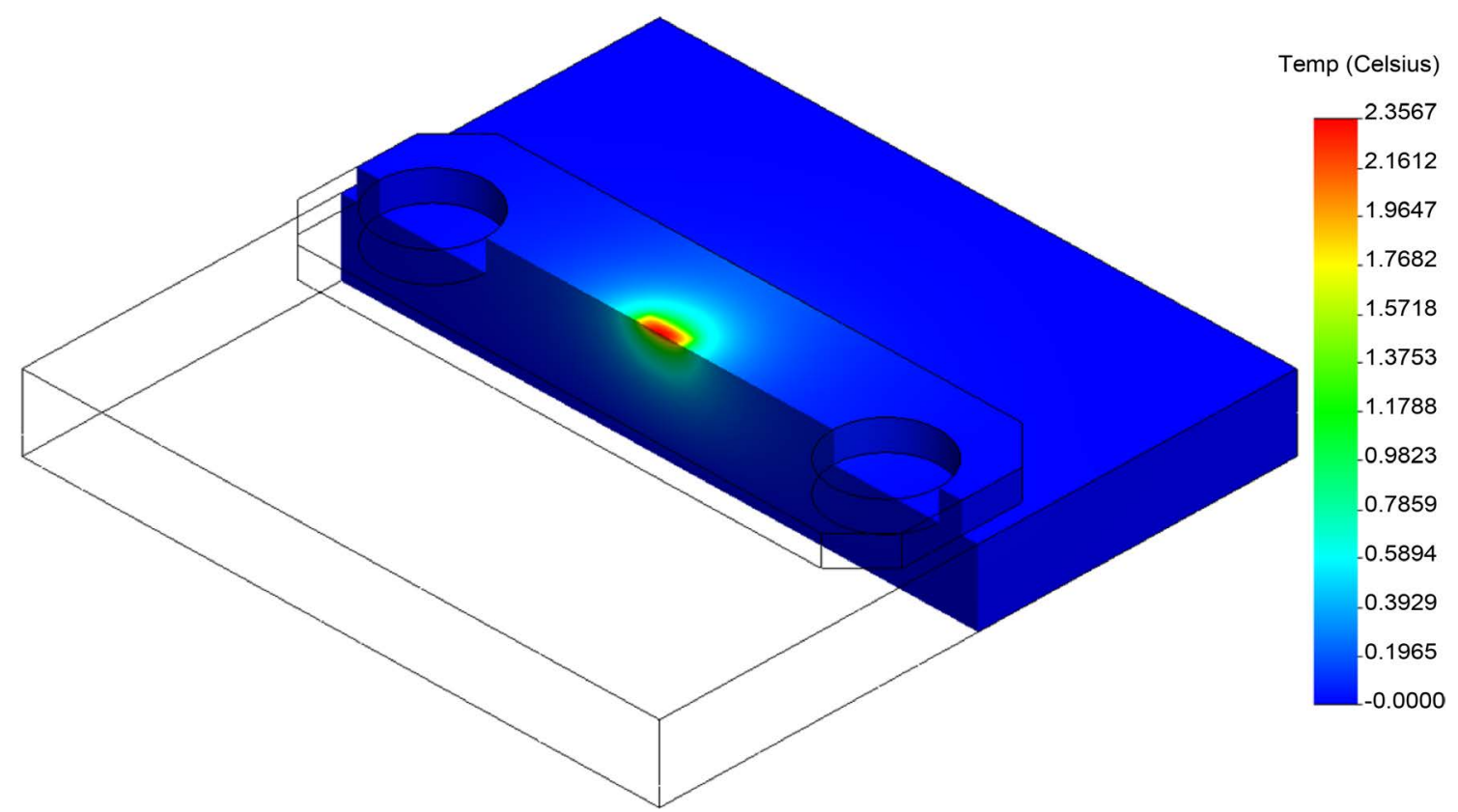

Figure 3. Thermal profiles from FEM simulation for the case of an aluminum 6061 base and $1 \mathrm{~mm} \mathrm{CuW} \mathrm{(20 \% /}$ $80 \%$ ) heat spreader.

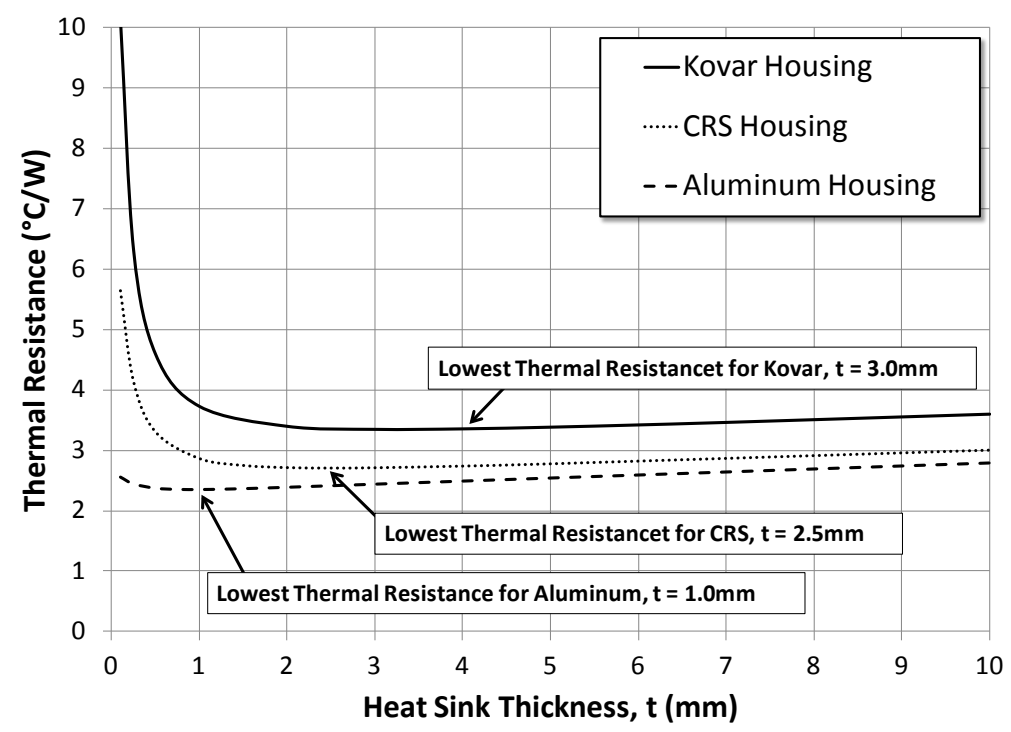

Figure 4. Heat transfer analysis results showing thermal resistance as a function of heat sink thickness and housing material type. 
figure that the thermal resistance decreases as the heat sink thickness increases for thicknesses below approximately $1-2 \mathrm{~mm}$. As thickness increases beyond the minimum thermal resistance point, the thermal resistance slowly increases.

\section{Optimum Heat Spreader Thickness for Electrical Performance}

When the HPA package is integrated into a module, at least one important electrical performance parameter is impacted by the choice of optimum heat spreader thickness. Namely, the ground inductance introduced by the signal path at the I/O tabs of the package. The inductive ground path is illustrated in Figure 5. It shows a cross section of the interconnect from the output of the package to module floor and transmission line in the printed circuit board (PCB) of the module. Note how the ground current must travel down the package heat spreader, through the housing floor, and back up to the transmission line ground of the PCB. This inductance is undesired since it creates an effective series inductance in the signal path. This creates an impedance mismatch and reduces the electrical bandwidth.

As can be seen in Figure 5, as the height of the heat spreader, $t$, is reduced, the current path is also reduced. The undesired inductance can impact port impedance match, gain, stability, and efficiency. For instance, in [10] [11] it was shown that proper impedance loads at harmonics affects the efficiency of the high power amplifier. For these reasons, minimization of the ground inductance is an important design consideration. For electrical performance reasons, the ideal thickness of the heat spreader is zero since that will minimize the inductive loop. However, this is certainly not acceptable for thermal reasons. As a result, a balanced design must be achieved.

\section{Optimum Design and Conclusions}

There are several important conclusions from this work. First, it was shown that an optimum design is required to simultaneously achieve the required junction temperature of the GaN amplifier devices and minimize the ground inductance. Second, it was shown that interconnect ground inductance reduces the operating electrical bandwidth. Third, for the specific case and package type illustrated in

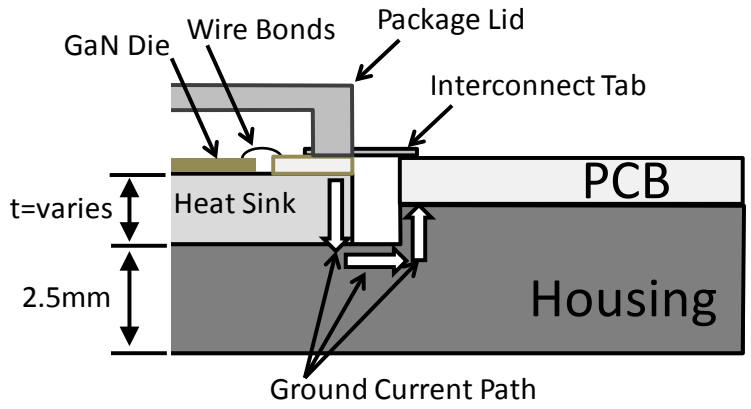

Figure 5. Illustration of the output signal ground current path which adds undesired series inductance. 
this work, the optimum spreader thickness is between $1-2 \mathrm{~mm}$. These lessons learned can be applied to other package types and at different operating frequencies.

\section{References}

[1] Sturdivant, R. (2013) Microwave and Millimeter-Wave Electronic Packaging. Artech House, Norwood, 148.

[2] Pribble, W.L., et al. (2002) Applications of SiC MESFETs and GaN HEMTs in Power Amplifier Design. IEEE MTT-S International Microwave Symposium Digest, 2-7 June 2002.

[3] Yu, X.M., Tao, H.Q. and Hong, W. (2016) A Ka Band 15 W Power Amplifier MMIC Based on GaN HEMT Technology. IEEE International Workshop on Electromagnetics, 16-18 May 2016.

[4] Gunjan, A., Thomas, K., Thomas, K. and Dana, W. (2016) Modeling and Analysis of Thermal Management in GaN HEMTs Using Microfluidic Cooling. Journal of Electronic Packaging, 139, 011001. https://doi.org/10.1115/1.4035064

[5] Noh, S.Y. and Bok, Y.I. (2016) A Linear GaN High Power Amplifier MMIC for Ka-Band Satellite Communications. IEEE Microwave and Wireless Components Letters, 26, 619-621. https://doi.org/10.1109/LMWC.2016.2585553

[6] Cen, Y.F. and McCann, D. (2012) $100 \mathrm{~W}$ GaN PA in Low Cost $3 \times 6 \mathrm{~mm}$ Plastic DFN Package Providing the Smallest “True SMT" Footprint for Pulse RADAR Applications. 7 th European Microwave Integrated Circuits Conference, Amsterdam, October 2012, 333-336.

[7] Pavlidis, S., Ulusoy, A.C. and Papapolymerou, J. (2015) A 5.4 W X-Band Gallium Nitride (GaN) Power Amplifier in an Encapsulated Organic Package. 45 th European Microwave Conference, Paris, September 2015, 789-792.

[8] Flucke, J., Schmuckle, F.J., Heinrich, W. and Rudolph, M. (2009) An Accurate Package Model for $60 \mathrm{~W}$ GaN Power Transistors. 4th European Microwave Integrated Circuits Conference, Rome, September 2009, 152-155.

[9] Halder, S., Kharabi, F., Howle, T., McMacken, J., Burns, C., LeFevre, M., Runton, D. and Gering, J. (2012) Broadband Lumped Package Modeling for Scaling Multi-Cell GaN HEMT Power Devices. 79 th Microwave Measurement Conference (ARFTG), Montreal, June 2012, 1-3. https://doi.org/10.1109/ARFTG79.2012.6291193

[10] Cheron, J., Campovecchio, M., Barataud, D., Reveyrand, T., Floriot, D., Stanislawiak, M., Eudeline, P. and Demenitroux, W. (2011) Harmonic Control in Package of Power GaN Transistors for High Efficiency and Wideband Performances in SBand. European Microwave Conference, Manchester, October 2011, 1111-1114.

[11] Cripps, S.C. (2006) RF Power Amplifiers for Wireless Communications. 2nd Edition, Artech House, Norwood. 
Submit or recommend next manuscript to SCIRP and we will provide best service for you:

Accepting pre-submission inquiries through Email, Facebook, LinkedIn, Twitter, etc. A wide selection of journals (inclusive of 9 subjects, more than 200 journals)

Providing 24-hour high-quality service

User-friendly online submission system

Fair and swift peer-review system

Efficient typesetting and proofreading procedure

Display of the result of downloads and visits, as well as the number of cited articles Maximum dissemination of your research work

Submit your manuscript at: http://papersubmission.scirp.org/

Or contact jectc@scirp.org 